\title{
Reform of Media Ownership Regulation
}

\section{Franco Papandrea}

$\mathrm{T}$ The Broadcasting Services (Media Ownership) Amendment Bill (the Bill), introduced in the Parliament by the Government on 21 March 2002, seeks to remove existing restrictions on foreign ownership of media assets, and to introduce the issue of exemption certificates for breaches of cross-media restrictions that satisfy prescribed minimum conditions on editorial separation of jointly controlled media operations. According to the Minister for Communications, Information Technology and the Arts (Alston, 2002), the aim of the Bill is to update Australia's outmoded media ownership regime in a way that encourages greater competition and use of new technologies while providing strict safeguards to ensure diversity of opinion and minimum levels of local news and information. How well do the proposed amendments live up to this laudable aim?

The Australian broadcasting industry, in all its forms, has been a target for extensive government regulation and control since its inception. Regulatory policy has been, and continues to be, the primary determinant of the structure and performance of the electronic media. While much of the regulation has been driven by social policy objectives and technical needs to minimise interference between users of the broadcasting spectrum, its effects have had important implications for competition, efficient use of resources and the range of services available to consumers. In addition, while the objectives of some of the regulatory instruments have consistent implications for industry performance, others are clearly in conflict with each other (for example, promotion of program diversity versus restrictions on entry). These conflicts have necessarily led policy makers to trade-off some of the objectives against others. According to the Productivity Commission (2000), this has produced 'a history of political, technical, economic and social compromises ... (whose) legacy of quid pro quos has created a policy framework that is inward looking, anti-competitive and restrictive'.

Given this complex set of compromises, reforms to rectify perceived problems with some aspect of the regulatory structure may well lead to some further distortions elsewhere in the structure. Further, because the proposals attempt to pursue multiple objectives they may be unnecessarily complicated. Although they purport to relax some of the ownership provisions of the current regulatory arrangements, they also seek to introduce prescriptive requirements in terms of diversity of opinion and local content. The desirability of the reform, therefore, would be difficult to determine without careful analysis of all its implications.

This paper seeks to examine the effects of the proposed media ownership changes. The main costs and benefits likely to be associated with the proposed

Franco Papandrea is Professor of Communication and Director of the Communication and Media Policy Institute at the University of Canberra. 
changes will be considered and will be used to assess whether a net benefit is likely to accrue to society. To provide the appropriate context for the examination of the proposals, the paper begins with a discussion of the existing ownership regulations.

\section{Current Media Ownership Regulation}

The ownership and control provisions of the Broadcasting Services Act 1992 (BSA) impose limits on media industry concentration that are much more onerous than those allowed by trade practices legislation for industry in general. The primary objective of these regulations is to ensure diversity of opinion and programming. Legislators have always been concerned about the power of the electronic media to influence public opinion. The Joint Parliamentary Committee on Wireless Broadcasting (1942), for example, was of the view that 'no medium of entertainment, whether it be stage, cinema or literature has such a powerful influence for good or evil as broadcasting'. With respect to foreign owners, the perceived risk is one of alien influence on the domestic culture and political system.

The concern with media influence on public opinion is primarily a product of the small number of suppliers of media services. While newspaper ownership concentration largely reflects the economics of the industry, concentration in the broadcasting media is primarily determined by the application of restrictive licensing and planning rules designed to protect incumbent broadcasters from entry competition. For example, an outright ban has been imposed on the licensing of new commercial television services until 2007, datacasting services cannot transmit programs likely to compete with those of commercial television services, the planning process arbitrarily restricts allocation of spectrum for broadcasting services, and the Australian Broadcasting Authority uses its licensing powers to limit the number of services. Without these restrictions on entry into broadcasting, there would be considerably less need for special ownership rules to promote media diversity.

Three principal mechanisms are currently used to control ownership of broadcasting media:

- $\quad$ First, the BSA imposes limits on the ownership of broadcasting media assets that can be held by an individual. For commercial television, no more than one station per licence area may be owned or controlled by an individual. In addition, the aggregate reach of television stations under common ownership cannot exceed 75 per cent of the Australian population. For commercial radio, no more than two stations per licence area may be owned or controlled by one individual.

- Second, cross-media limits prohibit common ownership of a controlling interest in television, radio and newspaper interests in the same market. An individual may own a controlling interest ( 15 per cent of the shares) in only 
one of these media in any one licence area. Ownership of a controlling interest in different media in different licence areas is permitted.

- Third, the BSA prohibits direct or indirect foreign ownership of a controlling interest in a commercial television licence or aggregate interests exceeding 20 per cent by two or more foreign interests. In addition, no more than 20 per cent of the directors of a company holding a commercial television licence may be foreign persons. For subscription television, the individual and aggregate share interests in a licensee company are limited to 20 per cent and 35 per cent respectively. No limits apply to the control of subscription television licences by foreigners. Commercial radio licences are not subject to foreign ownership or control regulation under the BSA. (Newspapers are subject to the foreign investment policy guidelines, which currently limit individual and aggregate foreign ownership of national or metropolitan dailies to 25 per cent and 30 per cent respectively and foreign ownership of provincial newspapers to 50 per cent.)

Only the cross-media ownership and foreign ownership provisions are affected by the proposed reforms, and the discussion in this paper will be confined primarily to those provisions.

\section{Effects of Current Ownership Rules}

Both the cross media rules and the limits on the ownership of broadcasting media assets reject the notion that diversity of opinion can be guaranteed by standard competition rules, particularly in a market without free entry and with few operators. By imposing ownership limits stricter than those likely to ensue in a competitive market, the regulations expand the number of suppliers in the market and thus trade-off benefits of economies of scale and scope for the perceived social benefits of diverse ownership of media assets. Although diversity of ownership does not necessarily guarantee diversity of views or programming (for example, ownership limits do not preclude different owners from entering into arrangements to share programming and related resources), the Productivity Commission (2000:314) observed that:

The public interest in ensuring diversity of information and opinion, and in encouraging freedom of expression in Australian media, leads to a strong preference for more media proprietors rather than fewer.

By prohibiting the formation of multimedia groups the cross-media rules inhibit firms from taking advantage of the associated economies of scope. These include the inability to maximise administrative efficiencies and reduce commercial risk by being involved in competing activities (rises and falls in demand for advertising in different media do not necessarily coincide). Under the current rules, the only way that media firms can pursue similar efficiencies would be to enter mutually beneficial cooperative or commercial arrangements with 
rivals. Examples of such co-operation include radio and newspaper groups sharing advertising personnel and parts of their premises, and radio and television stations sharing local news-gathering personnel, facilities and programs.

Cross-media regulation is inequitable in its application between powerful media. Pay television is not subject to cross-media ownership restrictions despite its steadily growing subscriber base. The Internet is also growing rapidly as a source of information but does not fall within the scope of the rules. Inequitable application is also evident in the print media - newspapers are subject to the regulation, magazines are not. While many magazines serve narrow interest groups, and thus have limited circulation, some of the more popular magazines have circulations that exceed those of some major daily newspapers. Such differential regulation of competitive activities can have a distorting effect on investment, particularly at times of rapid change, and can result in the development of inefficient industry structures.

The necessity of cross media rules is also being challenged by technological developments and the growth of new services. Digital television conversion has the potential to increase greatly the number of television services in the market. Pay television, which did not exist at the time the cross-media rules were introduced in 1987, is already a major mass medium. Although subject to the cross-media rules, the number of commercial and other radio services has grown substantially since 1987 . Over 2.3 million household have access to the Internet and the number is growing rapidly (ABS, 2001). In addition to providing access to new sources of information and entertainment, the Internet also provides access to many domestic and overseas radio services. With the expansion of broadband access to the Internet, access to television services will also be possible.

Assessment of the effectiveness of, or need for, cross-media rules must also take account of other regulatory instruments and policies that impinge on diversity. For example, although historically technical considerations have had an important influence on the number of potential entrants to the industry, they are no longer a significant constraint on entry. Removal of restrictions on entry, therefore, would facilitate entry into the industry and reduce the extent to which ownership restrictions may be needed to promote diversity. Considerations of what is an adequate level of diversity, of course, need also to take account of the services provided by the Australian Broadcasting Corporation (ABC) (operating one television and several radio nationwide networks) and the Special Broadcasting Service (SBS), both of which play an important role in media diversity.

Foreign ownership restrictions seek to ensure that commercial television services are controlled by Australians with the expectation that they are more likely to espouse opinions and favour programs that reflect Australian values. Reflection of Australian values (and the difficulty of defining them) is itself a moot point, quite apart from the question of whether media ownership regulation is the best way to achieve it. The restrictions apply only to ownership (not control) of pay television services. No foreign ownership restrictions apply to commercial radio services because they are considered to be less influential than 
television services. Foreign ownership restrictions affect not only foreign citizens and companies wishing to invest in Australian commercial and pay television services, but also any foreign-owned creditors of licensee companies taking equity positions in those companies or directorships on their boards. They may also prevent locally-owned investment funds (including superannuation funds) managed by the local subsidiaries of foreign-owned financial institutions from acquiring substantial interests in licensee companies.

Foreign ownership restrictions limit the capacity of commercial and pay television from gaining benefits of economy of scale and scope that may arise from being part of an international media conglomerate. By limiting the pool of potential investors in Australian media stocks the regulations may reduce the opportunities for licensees (and their shareholders) to maximise profitability and the realisable value of their licences. Other possible costs of the regulation include prevention of foreign companies from diversifying into Australian media assets and distortion of the debt/equity structure of licensee companies by favouring debt over foreign equity.

Ensuring majority Australian ownership of television does not necessarily guarantee programming that is sympathetic to Australian cultural values. Programming choices reflect commercial imperatives such as the program's price and attractiveness to audiences. If foreign programs have a substantial advantage in these respects, the nationality of a station's owner, or indeed its program manager, is likely to have little influence on program choice. A more effective means of ensuring Australian cultural values in television programming is to target that objective with specific regulation. To remain viable, even a fully a foreignowned licensee would have to comply with programming regulation as well as supply programs reflecting domestic tastes and preferences.

In any event, there are doubts about the effectiveness of the current regulation. In the current main case of foreign ownership of a television licensee company, compliance seems to be more apparent than real. Although CanWest (a Canadian company) has only a 14.99 per cent shareholding of the TEN network, additional interest in the form of 'subordinated and convertible debentures' give it a total interest in the group of 57.5 per cent (Productivity Commission, 2000). ${ }^{1}$

\section{Proposed Changes}

The main features of proposed changes to the media-ownership rules are the abolition of existing restrictions on foreign ownership and control of media assets and the introduction of exemption certificates from cross-media restrictions.

\footnotetext{
1 Although the ABA considers these arrangements to be compliant with the BSA, it did rule a 1997 attempt by CanWest to convert non-share interests to shares as being in breach of the Act.
} 


\section{Repeal of foreign ownership restrictions}

The Bill seeks to repeal existing foreign ownership and control restrictions applying to commercial and subscription television licences under the provisions of the BSA. With the repeal of the BSA restrictions on foreign ownership of commercial and subscription television licences will be subject only to the provisions of the Foreign Acquisitions and Takeovers Act 1975 consistent with the arrangements currently applying to commercial radio licences. The provision that broadcasting licences (commercial television and radio, and subscription television) may be held only by Australian companies (i.e., formed and registered in Australia) will not change.

When announcing the reform, the Minister noted that the 'Government is also committed to removing the current limits on the foreign ownership of newspapers' (Alston, 2002). These limits are currently in the form of policy instruments administered by the Treasurer and their alteration or removal does not require a change to legislation.

Removal of the foreign ownership restrictions is 'expected to broaden the scope for increased competition and improve access to capital and technology' for Australian broadcasting media (Explanatory Memorandum). Removal would also ensure consistent treatment of foreign investment in the media sector.

\section{Cross-Media Exemption Certificates}

According to the Explanatory Memorandum the 'cross-media reforms seek to allow increased scope for commercial opportunities while preserving a diversity of opinion and information which is of relevance to local communities'.

The Bill does not repeal the cross-media rules outright but introduces a mechanism to exempt specified non-compliant cross-media arrangements from breaches of the rules. The exemption certificates cover both ownership and control arrangements.

Essentially the exemption certificate is used to introduce a 'public interest' test to be satisfied by cross media-mergers. To satisfy the test, applicants are required to demonstrate that the merged entities will retain 'separate and distinct processes of editorial decision-making' as well as maintain a minimum (or existing if above the specified minimum) level of local television and radio news and current affairs.

Editorial separation is to be demonstrated through:

- $\quad$ publication of separate editorial policies for the merged entities;

- existence of accurate organisational charts in connection with editorial decision-making responsibilities at the time of the application; and

- maintenance of separate editorial news management, separate news compilation processes, and separate news gathering and interpretation capabilities. 
According to the Explanatory Memorandum these requirements do "not preclude sharing of resources or other forms of co-operation in newsgathering between organisations'.

The Bill does not provide guidelines or objective criteria about what is needed to satisfy the editorial separation requirements of the test. Applicants are instead required to make undertakings to satisfy the Australian Broadcasting Authority (ABA) that they are sufficient to guarantee editorial separation.

\section{How the Proposed Reforms Measure Up}

As noted by the Productivity Commission (2000), media regulation has developed as a complex set of compromises and trade-offs between competing objectives. In such a situation assessments of the efficiency of proposed changes cannot be carried out in isolation from the overall regulatory structure and needs to look carefully at all the related implications. This is not an easy undertaking. Albon and Papandrea (1998:81-82) suggest an approach to the evaluation of broadcasting regulation based on the following four guiding principles:

- regulation should be retained or introduced only when correction of market failure is strictly necessary and justified or to achieve a clearly identified social goal whose benefits to society clearly outweigh all the cost associated with the regulation;

- regulation should be based on a clear, well-defined, transparent and predictable framework;

- regulation should be directed to outcomes and not to the way in which the outcomes are generated or delivered; and

- regulation should be neutral in its impact on delivery technologies and on services with substantially similar attributes.

How well do the proposed reforms measure up against those principles? The Productivity Commission's inquiry undertook a comprehensive evaluation of all the regulations imposed under the BSA including foreign ownership and crossmedia restrictions. While the Commission favoured the repeal of both instruments, it recommended that the cross-media rules should be repealed only after other important conditions were met by the current regulatory structure for broadcasting, namely:

- removal of regulatory barriers to entry that prohibit more than three commercial television licences in an area;

- removal of economic planning criteria of section 23 of the BSA used by the ABA to determine the number of services to operate in a licence area;

- making spectrum available to enable new broadcasters to enter the industry;

- repeal of the foreign investment restrictions; and 
- introduction of a media-specific public interest test in the Trade Practices Act to apply to mergers and acquisitions. The test would allow only mergers and acquisitions demonstrated to be in the public interest with regard to diversity of ownership and diversity of sources of opinion and information.

The Productivity Commission's proposals provide a 'standard' that may be used to evaluate the efficiency of the proposed changes.

\section{Removal of constraints on foreign ownership}

The proposed repeal of the foreign investment restrictions is consistent with the Productivity Commission's recommendations and is a positive step towards facilitation of a more efficient industry. Repeal of the instrument will lead to consistent treatment of foreign investment in media assets and improve the industry's access to capital. It will also increase the pool of potential media proprietors and, in the longer term, it is likely to act as a constraint on media concentration. Until constraints on new entry into broadcasting are removed, repeal of the foreign investment restrictions will have little, if any effect on diversity of ownership in the media. Its immediate effect may simply be the replacement of domestic owners with foreign owners.

\section{Removal of cross media ownership constraints}

Assessment of the proposed repeal of the cross-media rules is more complex. The proposal satisfies only one of the pre-conditions recommended by the Productivity Commission (repeal of the foreign ownership restriction). It rejects the more important pre-condition of allowing and facilitating new entry in the media industry, and places considerable trust on the ability of a weak public-interest test (establishment of separate editorial policy structures for merged entities) to safeguard diversity of opinion.

Repeal of the cross-media rules under these circumstances, is almost equivalent to unqualified repeal, which according to the Productivity Commission (2000:364) 'would not be wise' because the Trade Practices Act, without the recommended media-specific public interest, would not be sufficient to guarantee diversity. According to the Productivity Commission 'facilitating entry of new players ... (and keeping) a careful eye on mergers between existing players' is critical to the preservation of diversity.

Apart from imposing a small, but ongoing, cost on media mergers and acquisitions, the requirement for an undertaking to establish separate editorial policy structures for merged media entities will be easily satisfied (the separate provision in the test for minimum news and current affairs output by regional merged entities will be discussed below). Even if full compliance with the required undertaking is assumed, the establishment of separate editorial policy structures will not constitute a sufficient condition for the delivery of diversity of opinion. The separate structures can only ensure that separate administrative processes are followed. Ultimately, the merged entities are commonly owned and 
it is the right of owners to 'hire and fire' editors and dictate to them the editorial policy to be followed. And that policy may be the same for all the entities under common ownership. The weakness of the proposed test is demonstrated by the newspaper operations of News Limited. The company owns a daily newspaper in several State capital cities each with its own separate editorial structure. Despite the separate structures, the newspapers are regularly collectively criticised for their common benign treatment of news that impacts on News Limited's business interests.

Although separate ownership of media entities will also not necessarily guarantee a diversity of opinion, it is more likely to be encouraged by a diversity of ownership than by common ownership. Repeal of the cross-media rules as proposed without repeal of mechanisms that prevent the entry of major new players in the media industry runs a considerable risk that diversity of opinion will be greatly reduced. The number of media proprietors will be constrained only by the combined effect of standard competition rules and the restrictions on commonly-owned television (one per area) and radio (two per area) licences in the same area and on the aggregate national reach of commonly-owned television licences. The possible effects in typical markets (television licence areas) are shown in Table 1.

Table 1: Possible Effect of Repeal of Cross-Media Restrictions

\begin{tabular}{|lccccc|cc|c|}
\hline \multicolumn{4}{|c}{ Number of Media Outlets per Market } & \multicolumn{3}{c|}{ Number of Owners } \\
\hline & \multicolumn{3}{|c}{ Television } & \multicolumn{2}{c|}{ Radio } & $\begin{array}{c}\text { Daily } \\
\text { press }\end{array}$ & $\begin{array}{c}\text { Current cross- } \\
\text { media rules }\end{array}$ & $\begin{array}{c}\text { No cross- } \\
\text { media rules }\end{array}$ \\
\hline Market & Comm. & National & Comm. & National & & Actual & Minimum & Minimum \\
\hline Melbourne & 3 & 2 & 9 & 6 & 2 & 13 & 12 & 7 \\
Sydney & 3 & 2 & 9 & 6 & 2 & 13 & 12 & 7 \\
Launceston & 2 & 2 & 2 & 4 & 1 & 7 & 6 & 4 \\
Wollongong & 3 & 2 & 2 & 4 & 1 & 8 & 7 & 5 \\
\hline
\end{tabular}

Note: It is assumed that limits on ownership of radio and TV licences in one area (two radio; one $\mathrm{TV}$ ) will be retained, and that the ABC and the SBS are separately controlled entities.

Source: Productivity Commission (2000)

The Explanatory Memorandum argues that the proposed public-interest test administered by the ABA is more objective and more effective than that recommended by the Productivity Commission. The primary reason for a publicinterest test to supplement consideration under the Trade Practices Act was a recognition that an economic or competition approach to defining media markets would not be sufficient to prevent concentration in diversity of information and opinion (the so called 'market for ideas'). The proposed test narrowly confines the public interest to the establishment of separate editorial structures in the 
merged entities and abandons considerations of plurality of ownership, the main criterion underlying the public interest as hereto defined. Thus, all other considerations of the desirability of media mergers will be judged only against the standard competition requirements of the Trade Practices Act. The relevant issue for consideration, therefore, is whether the undertakings for editorial separation will be sufficient to satisfy the public interest with respect to diversity of opinion. As noted above, it is doubtful that the proposed arrangements will provide an adequate guarantee that diversity will be sufficiently preserved.

The Explanatory Memorandum indicates that the proposed removal of the foreign investment limits will provide increased scope for plurality of ownership and that the growth of new sources of information such as the Internet will provide expanded choice. The first of these expectations is overly optimistic. With no new entry in the main media, removal of the foreign ownership limits can do no better than replace existing domestic owners with foreign owners. This means that exemption certificates for cross-media mergers will be the constraining factor for plurality of ownership and will almost certainly lead to a shrinking of the pool of potential assets available to foreign investor. The second expectation is only of limited validity. The regulatory concern to date has been to promote diversity of opinion among the main 'more influential' media. Magazines, for example, some of which have readerships larger than major daily newspapers, have never been included in the coverage of the cross-media rules. Although access to the Internet has grown rapidly in recent years, it has not yet reached the point (nor is it likely to do so in the short term) where its influence on opinion is comparable to that of main media.

Quite apart from these considerations, the proposal is bad regulation. Rather than being clear, direct and concise in its objective and application, it seeks to achieve a relatively simple outcome (separation of editorial structures in media mergers) via a cumbersome and indirect route. Notwithstanding the preceding discussion on the efficiency of the proposal, a requirement for editorial separation could be achieved easily and directly by making an independent editorial structure an eligibility condition for holding a broadcasting licence (where two radio licences in a single area are commonly owned as permitted by the current law, a single editorial structure could be permitted as an exemption). The cross-media rules could then be repealed altogether as under the proposed reform they do not appear to serve any purpose other than to provide a mechanism for the issue of exemption certificates consistent with the proposed public-interest test.

\section{Localism issues}

The proposed exemption certificates are also intended to provide a mechanism for the imposition of minimum requirements for news and current affairs on mergers involving regional broadcasting licences. This requirement is a reaction to community concerns about recent reductions in local news services by some regional television licensees, but is also related to wider localism policy issues in broadcasting. 
The principle of localism in broadcasting has proved difficult to implement, particularly when it has been in conflict with other competing priorities. In commercial television the principle was largely set aside in the late 1980s by two major policy initiatives. The first replaced the then existing ownership restriction, commonly referred to as the 'two-station rule', with a rule allowing common ownership of any number of stations with combined audience reach of 60 per cent (extended to 75 per cent in 1992) of Australia's population. The second, referred to as the 'equalisation' or 'aggregation' policy, provided for the aggregation of three adjacent regional monopoly licence areas into a single competitive licence area served by the three previously monopolist incumbents.

These policy changes provided strong incentives for stations in different parts of the country to combine into national networks for the distribution of programming. The strong incentives arise directly from the nature of the production costs of television programs. Virtually all of these costs are incurred in the production of the first copy of the program - the marginal cost of making additional copies is very small. Consequently, the average cost per unit of audience declines rapidly as the audience increases. Programs with limited audience appeal, therefore, have a considerable disadvantage vis a vis similar cost programs with larger audience appeal. Local news and current affairs would have little appeal to non-local audiences.

Initially after aggregation, the competing commercial television operators expanded their news services with local coverage in each of the pre-equalisation licence areas (that is, in most cases the number of services increasing from one per area to three per area). Limited audiences, however, meant that some of these programs were not financially attractive to television operators. As a result, recent cost-cutting measures by stations have led several to discontinue some of their local news services.

Rationalisation of local news services may be continuing and it is possible that services could be cut further. The ABA is currently conducting a public inquiry into the provision of local news services and will be reporting on what action, if any, may be required. Under the circumstances it may be wise to wait until the ABA has concluded its inquiry before action is taken via the proposed requirements for merged entities. It is difficult to speculate what the ABA may conclude from its Inquiry, but there are three broad possibilities:

- no action should be taken or is possible under current regulatory arrangements;

- $\quad$ specific local news output requirements are imposed on regional licensees as a condition of licence; and

- $\quad$ some other arrangement is proposed for the delivery of a local news service (for example, a subsidy for the production of a local news services allocated by tender to regional licensees).

In each case, all regional licensees would be equally affected by the policy initiative. 
The proposed arrangements, however, do not apply equally to all licensees. In most pre-equalisation licence areas, in addition to three commercial television services, there is a local newspaper and two commonly-owned radio services. The most likely merger possibility, therefore, is for one of the three television services to merge with the radio services and the local newspaper. This pattern would also be likely to emerge at the equalised licence area. As the proposed arrangement is concerned only with local television news and applies only to merged entities, it will impose a burden only on the merged television licensee. The other licensees are not affected. Furthermore, if the merged television entity was supplying more that the minimum requirement pre-merger it will be required to maintain the higher level post-merger and thus will be penalised with a bigger burden. In other words, the impact on television licensees will differ depending on their pre-merger situation.

For the same reason, the requirement will influence investment decisions by giving licensees without a local news service an additional incentive to merge. Indeed, the measure may be counterproductive in the shorter term. Licensees with a local news service planning to take advantage of the proposed reform of crossmedia rules would have an incentive to discontinue the service or reduce it to the minimum post-merger requirements in anticipation of entering into a merger.

The local news requirement also fails the test for good regulation. There is little evidence that the intervention is justified to correct market failure. In most areas there is at least one local television news service available to audiences. In addition, local news is available on radio services and possibly from a local newspaper. It may be possible that additional local news services are justified by a social goal. If so, that goal needs to be clearly defined and its benefits to society should clearly outweigh all the cost associated with the intervention. At the very least, consideration of the need for intervention should await the conclusion of the ABA inquiry.

Also, as already outlined, the proposed requirement is not neutral in its application. It applies only to television licensees that are involved in a media merger. Other competing television licensees and other services such as radio which supply local news services are not affected by the requirement. If intervention were justified, a more direct mechanism such as a licence condition applicable to all regional television operators would be more appropriate. Alternatively, if the intervention were intended to guarantee a minimum level of local television news, such a service could be more efficiently delivered via a production subsidy that could be tendered regularly by the competing operators. Such a mechanism would have the added advantage of specifying the quality requirements for the service. Under the proposed arrangement only the quantity is specified, which gives an incentive to affected licensees to minimise compliance costs by reducing the quality of the service. 


\section{Conclusion}

The proposals for media ownership reforms contained in the Broadcasting Services (Media Ownership) Amendment Bill do little to achieve their stated aim. The only element of the reforms likely to produce a positive contribution to the aim is the proposal to repeal the foreign ownership restrictions. Repeal of the restriction will increase the potential pool of investors in the media market and will bring treatment of foreign investment in the media industry in line with the treatment of other industries. However, it will do little, if anything, to increase media competition or add to diversity of opinion. Competition and diversity of opinion are closely related to the number of significant suppliers in the industry and while removal of the foreign ownership restrictions may lead to changes in the identity of owners there is no scope, in the short term at least, for it to increase the number of owners (unless current media holdings are broken up into smaller holdings). The number of suppliers in the media is controlled by other elements of the BSA that are not included in the reform.

There is a considerable risk that proposed reform of the cross-media rules will result in a net loss of social welfare and consequently it is unlikely to satisfy the fundamental principle that an intervention is justified only if it leads to a net benefit to society. The primary objective of the existing cross-media rules is to ensure diversity of opinion in influential media. De facto removal of the rules by the introduction of exemption certificates based on easily satisfiable conditions will be likely to lead to substantial reduction in the number of influential media suppliers with consequential loss of diversity. The separation of editorial structures in merged media entities is unlikely to be effective in maintaining diversity of opinion. The exemption-certificate mechanism is cumbersome and will add additional costs to industry operations as well as regulatory monitoring. The objectives of the features promoted by the exemption conditions could be achieved more efficiently by direct mechanisms such as conditions of licences administered by the ABA.

While the proposed cross-media changes do not appear to be justified, it does not mean that reform of the cross-media rules is not desirable. As noted by the Productivity Commission, there would be significant benefits to society if the cross-media rules were repealed in a manner that safeguarded desirable media diversity. This was only likely to be achieved if the removal of the rules was preceded by repeal of foreign-ownership restrictions, removal of all barriers to free entry to broadcasting, and introduction of a media-specific public-interest test against which media mergers and acquisitions were to be assessed to safeguard diversity of opinion. The proposed reform satisfies only the first of these preconditions. In that sense it is but a small step in the right direction.

\section{References}

Albon, R. and F. Papandrea (1998), Media Regulation in Australia and the Public Interest, Institute of Public Affairs, Melbourne. 
Alston, R., Senator the Hon (2002), 'Modernising Australia's Media Ownership Laws', Media Release 59/02, 21 March.

Australian Bureau of Statistics (2001), Household Use of Information Technology, Australia, Cat. No. 8146.0, ABS Canberra.

Broadcasting Services Act 1992, Commonwealth of Australia.

Broadcasting Services Amendment (Media Ownership) Bill 2002, The Parliament of the Commonwealth of Australia, House of Representatives.

Explanatory Memorandum, Broadcasting Services Amendment (Media Ownership) Bill 2002, The Parliament of the Commonwealth of Australia, House of Representatives.

Joint Parliamentary Committee on Wireless Broadcasting (1942), Report, Government Printing Office, Canberra (W. G. Gibson, Chair).

Productivity Commission (2000), Broadcasting, Report no. 11, Ausinfo, Canberra.

The author gratefully acknowledges helpful comments and suggestions by the CoEditor Graeme Wells and two anonymous referees. 